\title{
SPEED CONTROL OF THREE-PHASE IM BY V/F OPEN AND CLOSE LOOP METHOD
}

\author{
Vipul Gupta ${ }^{1}$, S. Phulambrikar ${ }^{2}$ \\ ${ }^{1}$ PG Scholar Dept. of Electrical EngineeringSATI,VIDISHAMadhya Pradesh, \\ Indiavipul2833@gmail.com \\ ${ }^{2}$ Associate Professor \& HODDept. of Electrical EngineeringSATI, VidishaMadhya Pradesh, \\ Indiasphulambrikar@rediffmail.com
}

\begin{abstract}
This paper presents the simulation method to control the speed of three phase induction motor by v/f method. Simulation model for speed control in both open loop and close loop is shown here because these motors are the most widely used electrical motor due to the reliability, cheaper cost and thew. Out of the several methods of speed control of an induction such as change of number of poles, variation in frequency, variable stator voltage, constant V/f control, variable rotor resistance, slip recovery method etc., the closed loop constant V/f speed control method is most widely used. Pulse width modulated inverter is the basic requirement of the scheme. Here first a PWM Inverter is modeled and its outputs is fed to the Induction Motor drivesA MATLAB SIMULINK MODEL was designed to successfully implement Open Loop V/f Control on a PWM-Inverter fed three-phase Induction Motor, and the torque is observed to be constant for various rotor speeds. Then a MATLAB model for Closed-Loop V/f Control on a PWM-Inverter fed 3-phase Induction Motor. It was noticed that using a Closed-Loop scheme with a Proportional Integral gave a superior way of controlling the speed of an Induction motor.
\end{abstract}

Keywords: Close loop control, Modelling, Matlab, Open loop control, PWM inverter, Simulink

\section{I.INTRODUCTION}

Three-phase induction machines are synchronous speed machines operating at below synchronous speed when motoring and above synchronous speed when generating. They are comparatievely less expensive to equivalent size synchronous or dc machines and range from a few watts to $10,000 \mathrm{hp}$. They indeed are the workhorses of today's industry. As motor they are rugged and require very little maintaince. However, their speeds are not easily controlled as with dc motors. They draw large starting currents, typically about six to eight times their full load values and operate with a poor lagging power factor when lightly loaded.

\section{OPEN LOOP STRATEGY}

For the open loop control of induction motor the voltage source inverter employing sinusoidal pulse width modulation technique is used, the output of inverter is feed to second order low pass filter prior to the motor as shown in block diagram figure 1.1.

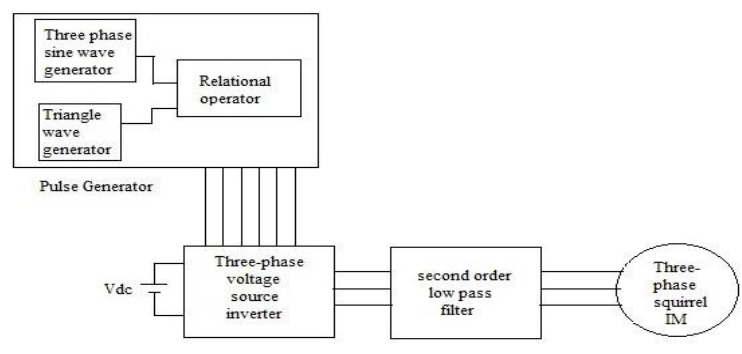

Fig 1.1 Block diagram of open loop method
As shown in above block diagram gate pulses for the inverter is generated by comparing the sine wave and triangle wave by the relational operator. whenever the sine wave amplitude is less than triangle wave it generates the output high otherwise low. For one leg of inverter the positive group switch is feed directly from output of relational operator and negative group switch is feed by NOT gate of same relational operator. Similarly for other two legs two more relational operator is used, in this way total six pulses are generated for six switches of inverter. Such pulses which are feed to inverter are shown in fig 1.2 below:

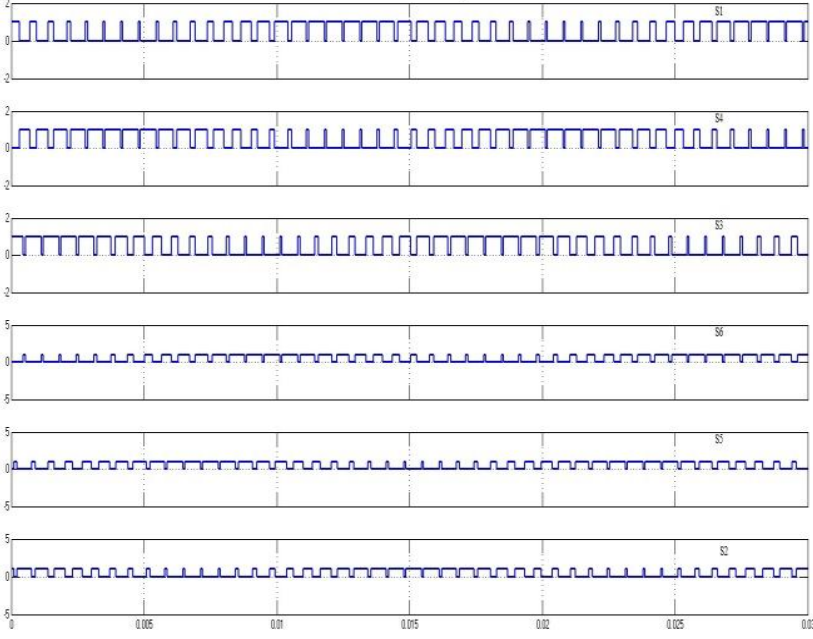

Figure 1.2 Pulses for inverter switches 


\section{CLOSE LOOP STRATEGY}

For closed loop control using v/f control of three phase induction motor, the control strategy is made in such a way that v/f ratio can be changed from $220 \mathrm{volth} / 60 \mathrm{~Hz}$ to

1) 198 Volts $/ 54 \mathrm{~Hz}$

2) 176 Volts $/ 48 \mathrm{~Hz}$

3) 132 Volts $/ 36 \mathrm{~Hz}$

First of all three phase sine wave is generated in such a way that its magnitude and frequency is changes automatically according to change in the circuit when required. Then these sine wave is compared with the triangle wave with help of relational operator and the six pulses for the inverter switches are generated. Inverter's output is feed to the induction motor via filter and line to line voltage from three phase inverter output is taken whose fundamental component is compared with the refrence voltage. The difference in these two voltages is applied to PI controller. A strategy is made in such a way that output of PI controller is then used for changing the value of amplitude modulation index which change the magnitude of sine wave and this signal now decide the new frequency of three phase sine wave also called refrence signal. Now new sine wave is compared with the triangle wave for different $\mathrm{V} / \mathrm{Hz}$ value.'

The complete block diagram which show the above said process is represented below in figure 1.3

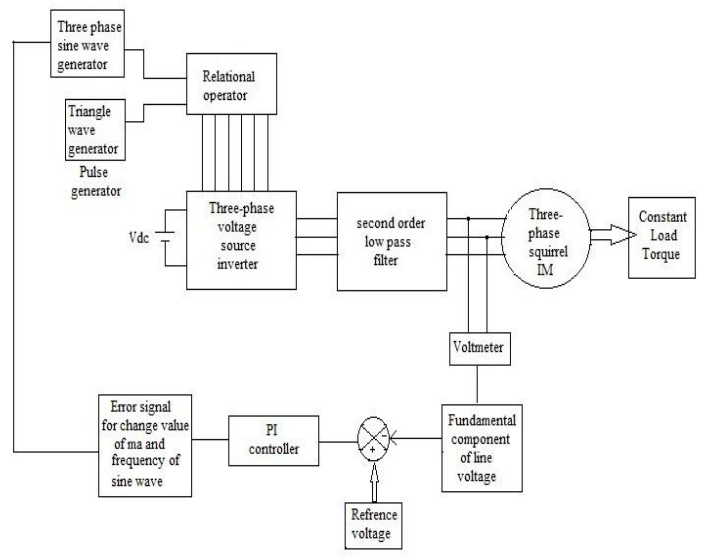

Figure 1.3: Block diagram for closed loop control of threephase induction motor

\subsection{Generation Of Three Phase Sine Wave :}

Sine wave is generated in such a way that its amplitude and frequency will change automatically according to the change in system voltage it is the reason here that we cannot use the voltage AC source as we do in open loop method Thus sine wave is generated by following system.

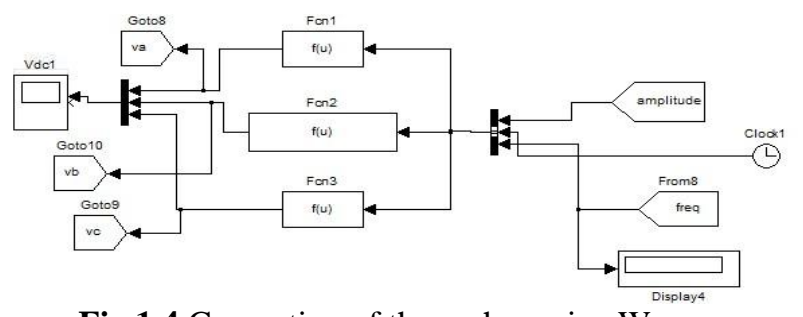

Fig 1.4 Generation of three phase sine Wave
Table 1.1 Description of Functions for sine wave generation

\begin{tabular}{|c|c|c|}
\hline S.no & Function name & Description \\
\hline 1 & Fcn 1 & $\begin{array}{r}\mathrm{u}[1] * \sin (\mathrm{u}[2] \\
\left.* 2 * \mathrm{pi}{ }^{*} \mathrm{u}[3]\right)\end{array}$ \\
\hline 2 & $\mathrm{Fcn} 2$ & $\begin{array}{r}\mathrm{u}[1] * \sin (\mathrm{u}[2] \\
\left.* 2 * \mathrm{pi} \mathrm{i}^{*} \mathrm{u}[3] 2 * \mathrm{pi} / 3\right)\end{array}$ \\
\hline 3 & $\mathrm{Fcn} 3$ & $\begin{array}{r}\mathrm{u}[1] * \sin (\mathrm{u}[2] * \\
\left.2 * \mathrm{pi}{ }^{*} \mathrm{u}[3]+2 * \mathrm{pi} / 3\right)\end{array}$ \\
\hline 4 & $\mathrm{u}[1]$ & $\begin{array}{c}\text { Amplitude } \\
\text { of Sine wave }\end{array}$ \\
\hline 5 & $\mathrm{u}[2]$ & $\begin{array}{r}\text { Clock signal } \\
\text { Frequency } \\
\text { of sine wave }\end{array}$ \\
\hline
\end{tabular}

The maximum value of sine wave corresponding to reference voltage is shown in Table 4.2.The corresponding value of 'ma' is also shown in this table. The output of PI controller is added in a constant value and the resultant of two is use to evaluate new value of $m_{a}$ which is multiplied in reference sine wave.

Table 1.2 Value of $\mathrm{m}_{\mathrm{a}}$ corresponding to particular value of reference voltage

\begin{tabular}{|l|l|l|l|}
\hline $\begin{array}{l}\text { Frequency } \\
\text { of Sine } \\
\text { wave }\end{array}$ & $\begin{array}{l}\text { Reference } \\
\text { line to line } \\
\text { voltage }\end{array}$ & $\begin{array}{l}\text { Maximum } \\
\text { value of sine } \\
\text { wave }\end{array}$ & $\mathrm{m}_{\mathrm{a}}$ \\
\hline 54 & 198 & 59 & 0.99 \\
\hline 48 & 176 & 58 & 0.90 \\
\hline 36 & 132 & 46 & 0.72 \\
\hline
\end{tabular}

The selection of frequency for the generation of sine wave with change in the reference voltage is implemented by a program written in the 'Matlab function' of User define library.

Here only the torqe speed characteristics having change in $\mathrm{v} / \mathrm{f}$ ratio from $220 \mathrm{v} / 60 \mathrm{~Hz}$ to $198 \mathrm{v} / 54 \mathrm{~Hz}$ at $\mathrm{t}=1 \mathrm{sec}$ is shown in figure.

\section{SIMULATION AND RESULT}

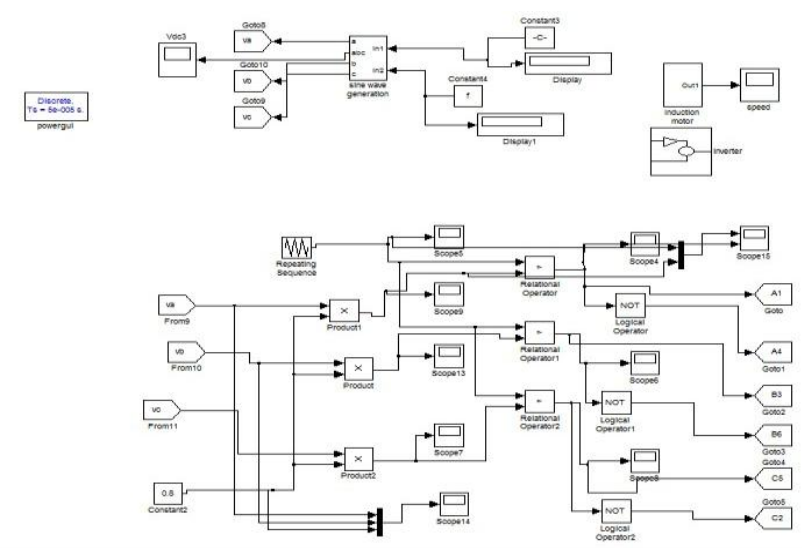

Figure 1.5 Simulink model of v-f speed control in open loop 

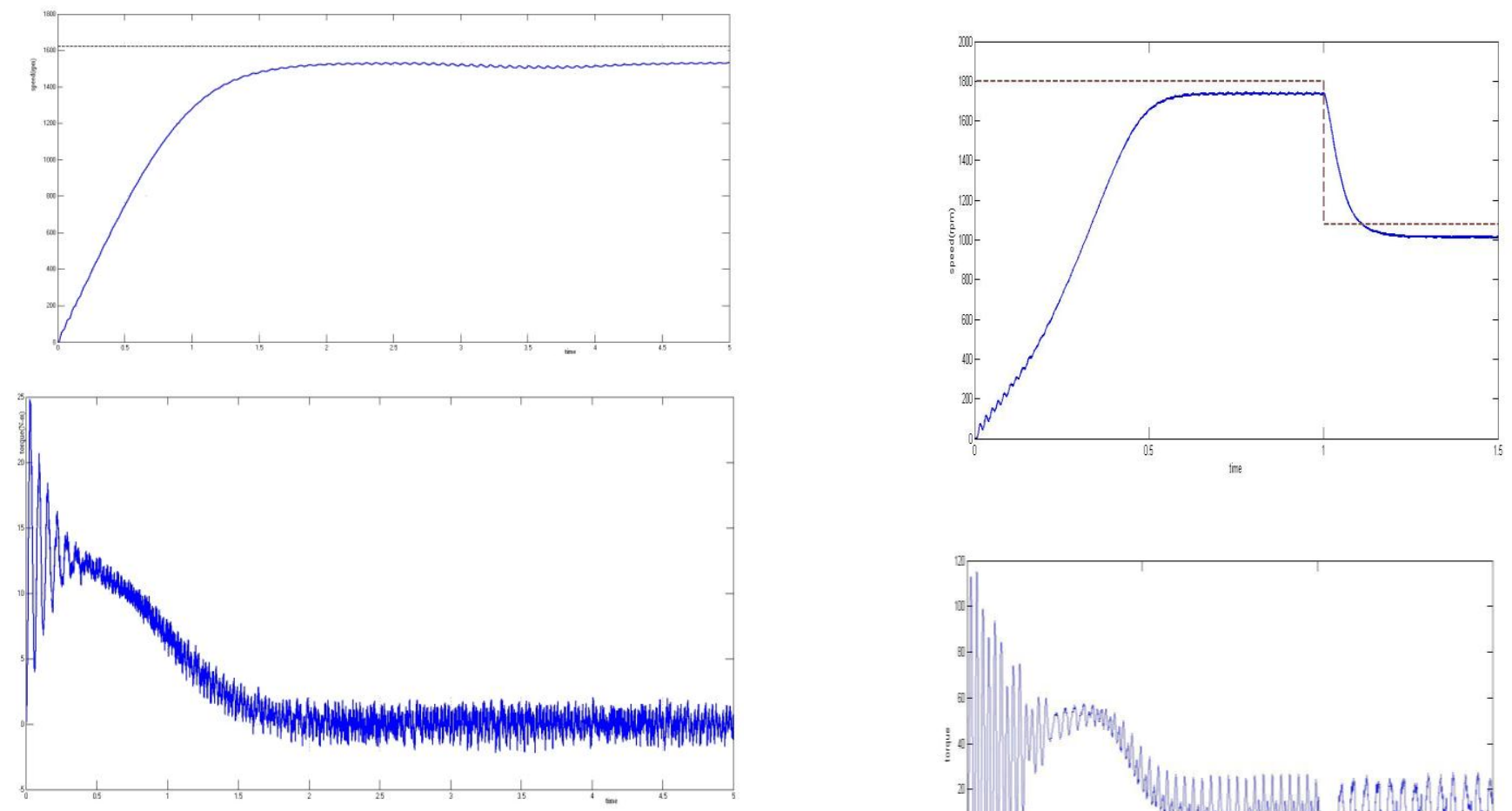

Figure 1.6 Speed (a) and torque(b) characteristics in open loop control
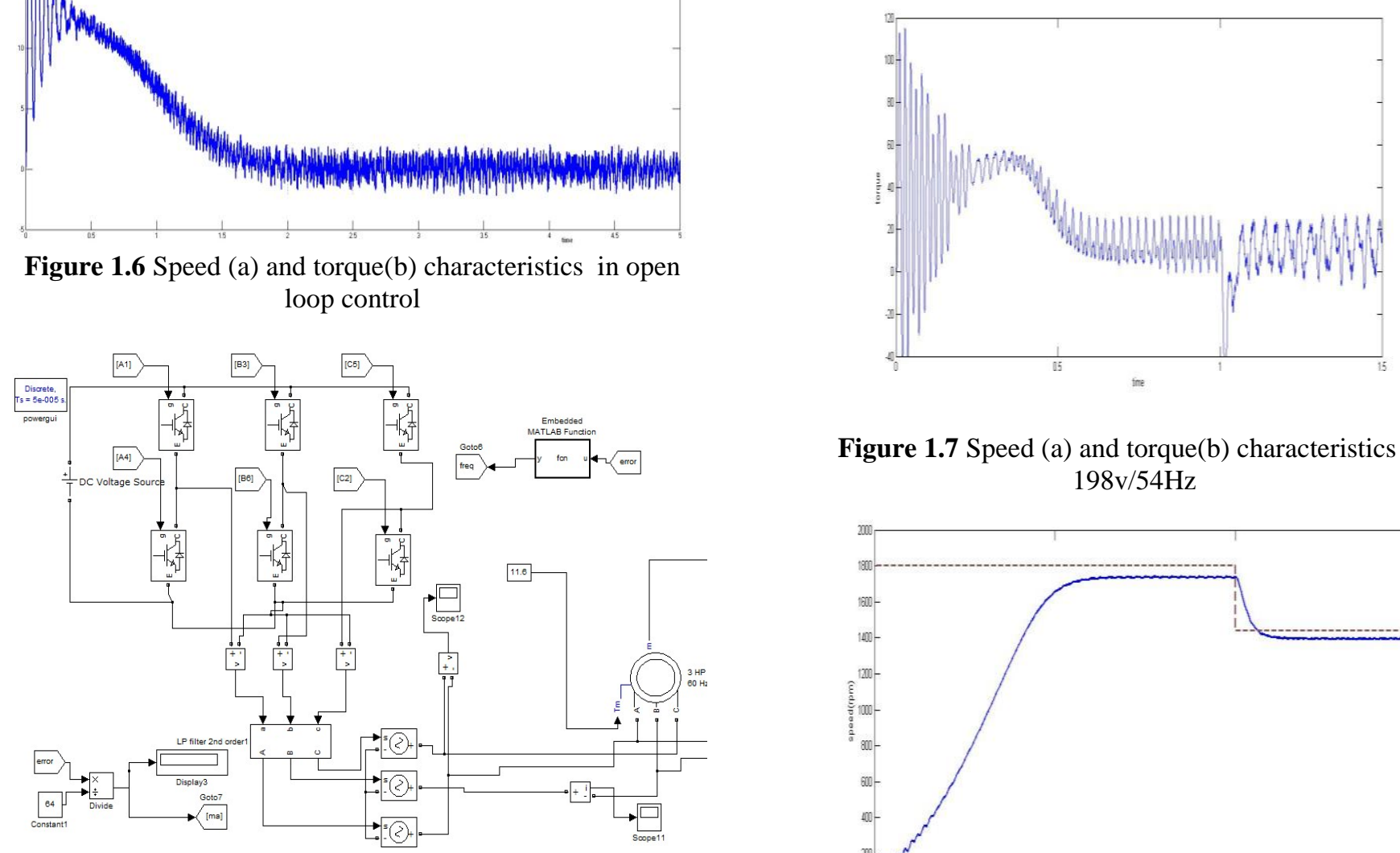

Figure 1.7 Speed (a) and torque(b) characteristics at $198 \mathrm{v} / 54 \mathrm{~Hz}$
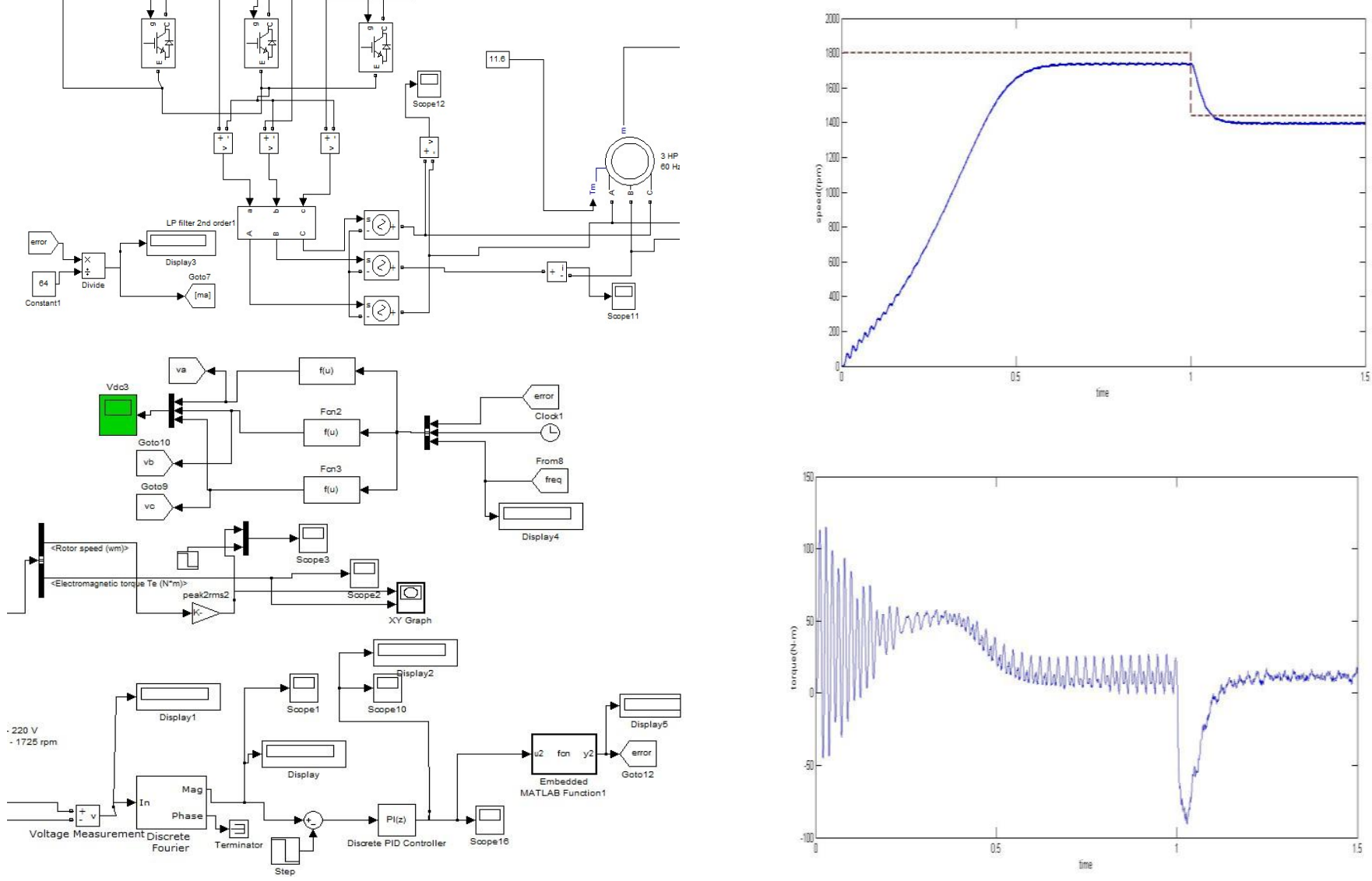

Figure 1.7 Simulink model of v-f speed control in close loop

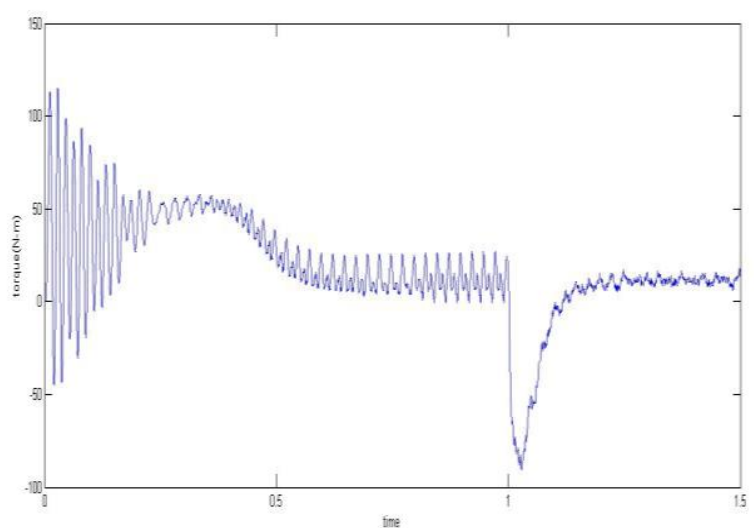

Figure 1.8 Speed (a) and torque(b) characteristics at $174 \mathrm{v} / 48 \mathrm{~Hz}$ 

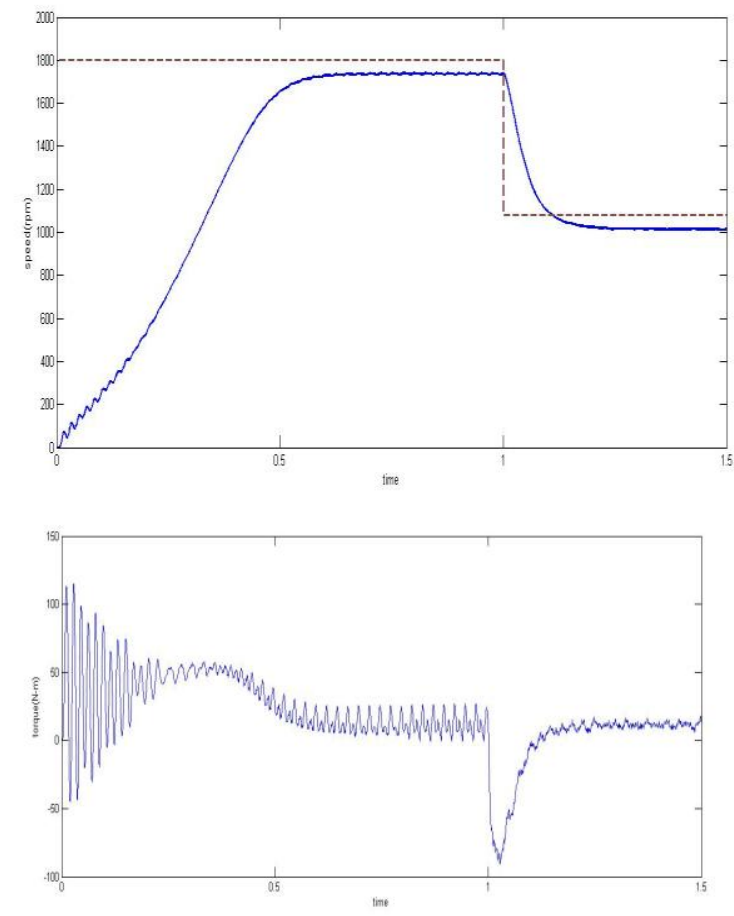

Figure 1.9 Speed (a) and torque(b) characteristics at $132 \mathrm{v} / 36 \mathrm{~Hz}$

\section{CONCLUSION}

Speed of 3- phase Induction model is controlled successfully both in open and close loop method. The PWM signals were generated in controlling technique by comparing either a triangular waveform with a sinusoidal waveform using relational operators. An Induction Motor was run with the help of a PWM Inverter for implementing the speed control mechanisms and the various characteristic curves were obtained. It was observed that there were a lot of transient currents in the stator and rotor at the time of starting and they took some time to settle down to their steady-state values. Open-loop V/f Control was implemented using MATLAB. Closed-loop V/f Control used a Proportional Integral to process the error between the actual rotor speed and reference speed and used this to vary the supply frequency. The Voltage Source Inverter varied the magnitude of the terminal Voltage accordingly so that the $\mathrm{V} / \mathrm{f}$ ratio remained the same. It was observed that again the maximum torque remained constant across the speed range. Hence, the motor was fully utilized and successful speed control was achieved.

\section{REFERENCES}

[1]. Adel Aktaibi \& Daw Ghanim, "Dynamic Simulation of a Three- Phase Induction Motor Using Matlab Simulink,"

[2]. P. C. Sen, "Princibles of Electric Machines and power electronics", Wily, 2nd edition, 1996.

[3]. R. Krishnan, "Electrical Motor Drives: modeling, analysis and control", PHI

[4]. Sushma, P. ; Samaga, B.L.R. ; Vittal, K.P. "DQ Modeling of Induction Motor for Virtual Flux Measurement" IPEC, 2010 Conference Proceedings , 2010 , pp. $903-908$
[5]. A Dumitrescu, D.Fodor, T.Jokinen, M.Rosu, and S.Bucurencio, "Modeling and Simulation of electric drive system using Matlab/Simulink environments," international Conference on Electric Machines \& Drives (JEMD), 1999, pp.451-453.

[6]. M.L.de Aguiar, and M.M.Cad, "The concept of complex transfer functions applied to the modeling of induction motors," Power Engineering Society Winter Meeting, 2000, voU, pp.387-39I.

[7]. Nabae, I. Takahashi and H. Agaki, "A New NeutralPoint-Clamped PWM Inverter," IEEE Transactions on Industry Applicaitions. Vol.IA-17, No.5, Sep./Oct., 1981, pp.518-523.

[8]. Reddy M. H. V. and Jegathesan V., "Open loop V/f control of induction motor based on hybrid PWM with reduced torque ripple," International Conference on Emerging Trends in Electrical and Computer Technology , pp.331-336, March 2011.

[9]. Arulmozhiyal, R. Baskaran, K. Devarajan and N. Kanagaraj, "Space Vector Pulse Width Modulation Based Induction Motor Speed Control Using FPGA," ICETET, 16-18 Dec 2009, pp 242-247.

[10]. P. C. Krause, O. Wasynczuk, S. D. Sudhoff "Analysis of Electric Machinery and Drive Systems", IEEE Press, A John Wiley \& Sons, Inc. Publication Second Edition, 2002.

[11]. P.C. Krause and C. H. Thomas, "Simulation of Symmetrical Induction Machinery", IEEE Transaction on Power Apparatus and Systems, Vol. 84, November 1965, pp. 1038-1053.

[12]. J. O. P. Pinto, B. K. Bose, L. E. B. Silva, M. P. Kazmierkowski, "A neural-network-based spacevector PWM controller for voltage-fed inverter induction motor drive," IEEE Transactions on Industry Applications, vol. 36, no. 6, Nov./Dec. 2000, pp. 1628-1636. 